\title{
EFEITOS DA CALAGEM E DA MATÉRIA ORGÂNICA SOBRE A ACIDEZ DE CINCO SOLOS DO MUNICÍPIO DE PIRACICABA
}

\author{
FLÁVIO MARCOS ROSATO \\ Eng. ${ }^{\circ}$-Agr. ${ }^{\circ}$
}

Orientador: Francisco de Assis Ferraz de Mello

Disserłação apresentada à Escola Superior de Agricultura "Luiz de Queiroz", da Universidade de São Paulo, para obtenção do título de Mestre em Solos e Nutrição de Plantas.

\footnotetext{
P I R A I C A B A

Estado de São Paulo - Brasil

Setembro, 1978
} 
A minha esposa,

Maria Elisabete

$D E D I C O$ 
i i.

Ao Professor Dr. Francisco de Ass is Ferraz de Mello, pela amizade e orientação;

A Universidade de São Paulo e à Escola Superior de Agricultura "Luiz de Queiroz";

Aos Sr. Vinicius ferraz, pelos serviços de anälise de laboratório e Angelo Smaniotto, na coleta de amostras de solos

Ao Cunhado Francisco Vitor Bedusqui Orsi, aos primos Orlando Quidetti Junior e Victor Benito Beduschi, pelo auxilio pres tado durante o trabalho de laboratōrio;

E a todos os que direta ou indiretamente colaboraram para a realização deste trabalho. 
RESUMO $\ldots \ldots \ldots \ldots \ldots \ldots \ldots \ldots \ldots \ldots \ldots \ldots \ldots \ldots \ldots \ldots \ldots \ldots \ldots$

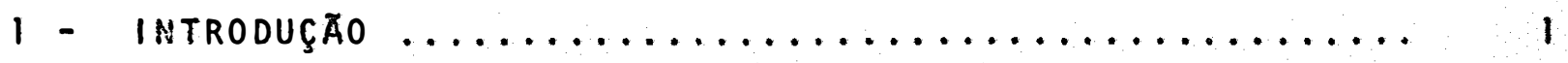

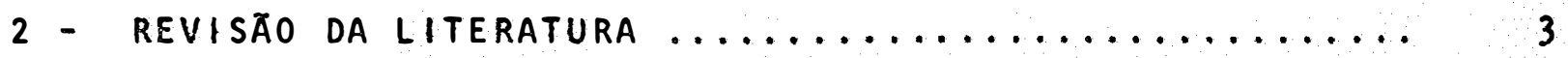

2.1 - o Método do Al Trocävel ................ 3

2.2 - A Matēria Orgânica e a Acidez do Solo ....... 5

3 - MAterials e metodos $\ldots \ldots \ldots \ldots \ldots \ldots \ldots \ldots \ldots \ldots \ldots \ldots$

3.1 - Solos e Adubos Utilizados ............... ?

3.2 - Condução do Experimento ............... 12

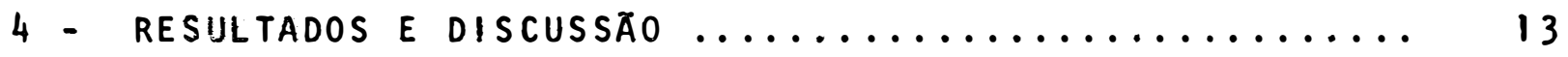

4.1 - Efeitos do $\mathrm{CaCO}_{3}$ sobre o pH das Terras ...... 13

4.2 - Efeitos da Matéria Orgânica sobre o pH das Terras ........................ 16

4.3 - Efeito sobre o $\mathrm{pH}$ do $\mathrm{CaCO}_{3}$ Dentro de Matéria Orgânica e da Matéria Orgânica Dentro

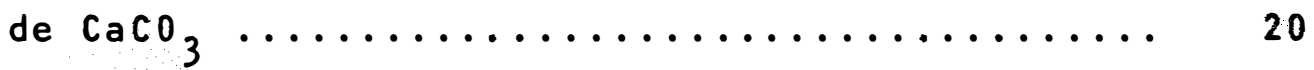

4.4 - Efeitos do $\mathrm{CaCO}_{3}$ sobre os Teores de $\mathrm{Al}^{3+}$

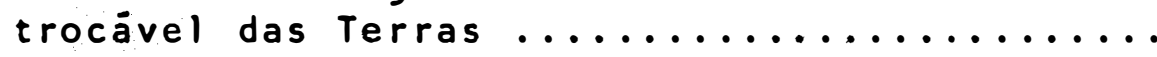

4.5 - Efeitos da Matēria Orgânica sobre o Teor

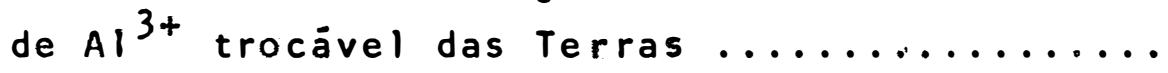

4.6 - Efeitos sobre os Teores de Al trocável do $\mathrm{CaCO}_{3}$ Dentro de Matēria Orgânica e da Matëria Orgânica Dentro de $\mathrm{CaCO}_{3} \ldots \ldots \ldots \ldots \ldots$ 
Pàgina

4.7 - Efeitos do $\mathrm{CaCO}_{3}$ sobre os Teores de H Total

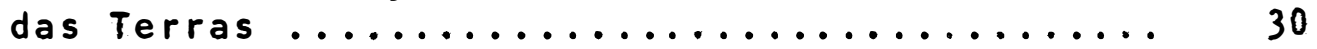

4.8 Efeitos da Matēria Orgânica sobre os Teores de $H$ Total das Terras .................. 32

4.9 - Efeitos sobre os Teores de $\mathrm{H}^{+}$Total do $\mathrm{CaCO}_{3}$ dentro de Matéria Orgânica e da Matëria Orgâa nica dentro de $\mathrm{CaCO}_{3} \ldots \ldots \ldots \ldots \ldots \ldots \ldots \ldots \ldots \ldots$

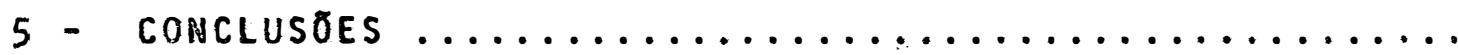

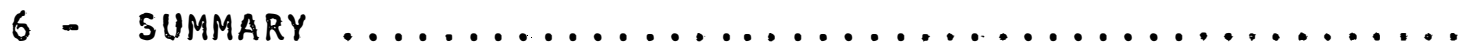

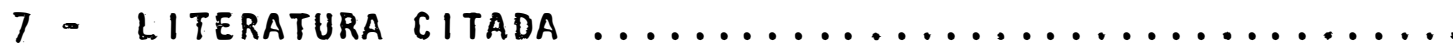


RESUMO

Esta dissertaça äo se refere a um experimento fatorial $2^{4}$ $\mathrm{CaCO}_{3} \times$ matéria orgânica, sob a forma de torta de alsodão.

As quantidades de $\mathrm{CaCO}_{3}$ foram calculadas pelo método do Al trocāvel, utilizando o fator 1,5 e foram as seguintes: 0,1, 2 e 3 vezes as necessárias para eliminar o Al trocável das terras .

As quantidades de matéria orgânica foram iguais a 0 , 15 , 30 e 45 t/ha, considerando-se a densidade aparente das terras igual a 1,5 e a nrofundidade de $20 \mathrm{~cm}$. As terras utilizadas são do municinio de Piracicaba: 
Grande Erupo

Hidromórfico associado com IVG orto

Terra Roxa Estruturada fase rasa

Latosol Roxo

Regosol "intergrade" para PVA var. Laras

Hidromörfico associado com PVA var. Laras
Série

Três punicípios

Pau D Alho

Ir acema

Cruz Alta

Formigueiro

0 experimento foi realizado em vasos com $1 \mathrm{~kg}$ de terra, sob condições de 1 aboratório, permanecendo as terras ümidas (cer ca de $50 \%$ do poder de retenção de umirade) durante 30 dias. Após esse periodo foram secas, destorroadas e peneiradas. A seguir, procederam-se as determinações de $\mathrm{pH}$; Al trocável e H total.

Concluewse que:

a - O método do Al trocável recomendou quantidades pequenas de calcārio, insuficientes para eliminar totalmente o Al trocável des terras e só na ausência de matēria orgânica elevou eficazmente o pH, sem exercer efeitos apreciảveis sobre a acicez total.

b - A matêria orgânica aresentou tendência geral de elevar o pH das terras, tendo sido dübio os seus efeitos sobre os teores de Al trocável e H total. 


\section{1 - INTRODUÇAOO}

São Paulo é um Estado em nue a maior partedos solos a presenta reação ācida, às vezes com teores elevados de Al trocável (COELHO e VERLENGTA, sem data, p. 139 ; COMISSÃODE SOLOS, $1960 ;$ GARGANTINI et alii, 1970). Por isso, um dos problemas mais frequentes que os agricultores paulistas enfrenta é o controle do $\mathrm{pH}$ de suas terras. Fste Eato, aliás, é extensivo à maioria dos solos brasileiros.

Há cerca de uma década (KAMPPATH, 1967) foi introduzido no Brasil, e em värios outros países, o mêtoda do Al trocável para a determinação da quantidade de calcārio a ser empregada em determinada gleba a ser cultivada. Entretanto, não foram efetuadas experimentações preliminares para testar a validez desse méto 
do nas condições de solo e de clima de são paulo e, menos ainda, do Brasil.

O método do Al trocável consistia em se determinar o nü mero de e.mg de Al trocävel, por $100 g$ de terra a multiplicá-10 por 1,5. O produto obtido seria igual ao número de t/ha de calcá rio comum a ser empregado.

Por outro lado a natureza do clima do Estado de São Pau 10 e da maioria dos estados brasileiros, com temperaturas elevadas faz com que a matéria orgânica adicionada se decomponha com grande rapidez (YENNI, $1941, \mathrm{p}, 197$ ). E é sabido que esta desempenha papel relevante na fertilidade do solo.

A este respeito, entre outras funções desempenhadas, a matéria orgânica ao se decompor dá origem a diversos ácidos orgânicos e fenóis que são componentes da acidez do terreno, (MELLO et alii, sem data, p. 52). Tntão, o seu emprego acarretaria aci dificação do solo.

Em vista do que ficou exposto surgiu a idéia da realiza ção deste trabalho, cuja finalidade é a de fornecer dados prelimi nares para se constatar a validez do método do Al trocável para a correção da acidez de nossos solos e dos efeitos da matéria orgânica sobre a acidificarão dos mesmos. 


\section{1 - 0 Método do A1 Trocấvel}

Este método geralmente recomenda o uso de ouantidades re lativamente pequenas de calcảio e visa anenas eliminar o Al trocável do solo, que pode se tornar tóxico às blantas, quando accima de certa concentração. No Estado de são paulo considera-se q̧ue tal concentração é igual a 0,5 e.mg/100\& de terra (GARGANTMI et alii, 1970).

Um dos primeiros trabalhos feitos no Brasil para testar a eficiência do método em apreço foi o de strvin (1971). Esse autor concluiu que utilizando o Eator 1,5 , o plas terras com que trabalhou chegou aproximadamente a 5,8 , mas não eliminou total mente o Al trocável e nem o Hextraido com ecetato de amônio. 
CATANI e ALONSO (1989), trabalhando com solos do Estado de São Paulo, concluiram que quando o platinge a 5.7 o solo já não possui mais Al trocável.

PITTA (1974) constatou que com a utilização do fator 1,5 não houve eleçação sensível do nY das terras com que trabalhou e nem da acidez titulável ( $A 1+H$, extraílos com solução de acetạ to de amônio). 0 teor de Al trocävel baixou bastante em añenas dois solos.

MELlo (não publicado), utilizando dados disponíveis da literatura concernente a solos do Estado de são Paulo e do Paraná, concluiu que a ausência do Al trocāvel se dará a pll 5,5. Quando o pl era de aproximadamente 5,2 o teor de Al trocável estava ao re dor de 0,5 e.mg/100 g de terra, portanto, jä no limiar da toxidez. Baseado nos dados de GERVI (1971) , NELLO (1974) constatou que o uso do fator 2 , em vez de 1,5 , condusia a resultados semelhantes aos obtidos pelo método descrito por CATANI et ali (1955), o qual visa a elevar o nil a cerca de 6,5.

Como a utilizaça do fator 1,5 geralmente resulta numa subcalagem, atualmente são empregados fatores maiores, 2 ou 3 . Se, com, este procedimento, os teores de Ca + Mg trocáveis não atingirem um nível conveniente, então se aplicam çuantidades adicio nais de calcärio, atē que os teores desses elementos no solo se tornem satisfatórios (PIPAENr, 1972 : VAR PAIJ, 1975 ; COMISSÃO ES TADUAI. DE FERTILIDADE DE SOLOS, sem data). 


\subsection{A atéria Orrânica e a Acidez do Solo}

Enbora durante a decomposiça no solo de matéria orgâni ca adicionada sem fermentação prévia formem-se muitos àcidos orga nicos e fenóis, dois componentes da acidez potencial, vârios trabalhos têm revelado que o grocesso em referência conduz a uma ele vação, pelo menos temroräria, do grl. Talvez até seja esse um dos motivos da elevação do pr do solo quando incorporado de vinha ça (ALIEIDA et alii, 1950), pois esta é um resíduo rico de matèria orgânica.

os autores mencionacos constataram que na dose de 500.000 litros por ha o pri de terra com que trabalharam, que ini cialmente era 5,47 , passou a ser maior nue 7,00 , fosse a vinhaça sulfúrica, fosse a vinhaşa neutralizada com leite de cal.

ALNEIDA et alii (sem data) concluiram, em trabalho pos terior: porém utilizando a mesma terra arenosa do ensaio anterior e vinhaça sulfürica, que o pll variava linear e significativanente com o volume de vinhaça empregado, segundo a equação seguinte:

$$
y=4,98+0,20 v
$$

onde $\underline{y}$ e o $p H$ e $\underline{v}$ o volume de vinhaça.

VALSECHI e PIPENTEL GOMES (1954) concluiram que a vinha ça, além de elevar o pll da terra determinava uma radução sensível de total da mesma.

DÖBEREINER e ALVAHYDO (1966) constataram que a casca de arroz e grama fresca misturadas elevaram o pl de un solo "Gray Ilidromór śco". Entretanto. sacarose aplicada ao mesmo solo causava abaixamento do pE. 
EIRA e CARVALHO (1970) tambêm concluiram que sacarose determinava reduça no nIr do solo, enquanto que palha de cana e torta de algodão ag̣iam de modo diverso.

PAZ et alii (1977) utilizando amostras de Rogosol Sertãozinho e do Latossolo Roxo de Iracemäpolis (PANZANI et alii, 1966), num ensaio de incubação com doses crescentes de torta de mamona, concluiram que esta causava forte aumento do ph e forte redução de F total dos mesmos.

ZAGo et alii (não purlicado) estudaram os efeitos da tor ta de mamona sobre algumas propriedades de dois Latossolos do Esta do de São Paulo. Observaram notável elevação do pll e tendência de redução da acidez total. Entretanto, os dados relativos ao Al tro cável não permitiram uma conclusão geral.

Utilizando restos de cultura de milbo, como fonte de ma. téria orgânica, MELLo et alii (não publicado, b) constataram que doses crescentes desse material causaram elevação dos pHs e redu ção dos teores de Al trocävel de cinco solos do municínio de Piracicaba.

MELLO et alii (não nublicado, a) estudaram os efeitos de torta de mamona sobre algumas propriedades de cinco solos do mu nicípio de Piracicaba e, no que respeita aos pHs, constatam ele vações significativas de acordo com as doses de torta aplicadas.

Todos os trabalhos citados neste subcanitulo, 2.2 , são de incubação, cujos períodos variaram de um para outro: tais períodos, contudo, não foram muito grandes, no máximo de 45 dias. 
3.1 Solos e Adubos Utilizados

Ilo presente trabalho foram utiliaadas terras provenien tes das camadas superficiais dos seguintes solos do lunicipio de Piracicabas

\section{Grande Crupo}

Midromórfico associado com LVE orto

Terra Rora Estruturada fase rasa

Latosol Roxa

Regosol "intergrade" para PVA var. Laras

Widromórfico associado com PVA var. Laras
Sërie

Três Prunicínios

Pau I'Alho.

Ir acema

Cruz Altz

Formigueiro 
As Tabelas 1 e 2 apresentam algumas caracteristicas fisicas e quimicas das terras emregadas no trabalho.

TABElA 1 - Composição granulométrica das terras utilizadas (RANZANI et $a$ Zi $i, 1966$ )

\begin{tabular}{lccc}
\hline Solo & Componentes oranulométricos & $(\%)$ \\
\cline { 2 - 4 } & Areia & Limo & Argila \\
\hline Três Municípios & 19,4 & 26,9 & 53,7 \\
Pau D'Alho & 29,1 & 45,0 & 25,9 \\
Iracema & 27,8 & 26,1 & 46,1 \\
Cruz Alta & 89,4 & 5,1 & 5,5 \\
Formigueiro & 74,0 & 12,1 & 13,9 \\
\hline
\end{tabular}


TABElA 2 - Algumas características quimicas das terras utilizadas

\begin{tabular}{|c|c|c|c|c|c|c|c|c|}
\hline \multirow{3}{*}{ Solo } & \multirow{2}{*}{$\mathrm{pH}$} & \multirow{2}{*}{ C $\%$} & \multirow{2}{*}{$\begin{array}{l}\mathrm{PO}_{4}^{3-} \\
\text { Solūvel }\end{array}$} & \multicolumn{2}{|c|}{ Trocáveis, } & \multicolumn{3}{|c|}{ e.mg $/ 100 \mathrm{~g} \quad \mathrm{TFSA}$} \\
\hline & & & & $\mathrm{k}^{+}$ & $\mathrm{Ca}^{2+}$ & $\mathrm{Mg}^{2+}$ & $\mathrm{Al}^{3+}$ & $\mathrm{H}^{+}$ \\
\hline & & & & & & & & \\
\hline Três luuni cípios & 5,4 & 1,62 & 0,07 & 0,52 & 3,20 & 1,76 & 1,04 & 5,60 \\
\hline Pau $D^{8}$ Alho & 6,0 & 1,65 & 0,06 & 0,48 & 23,00 & 3,16 & 0,03 & 4,00 \\
\hline Ir acema & 5,5 & 2,07 & 0,03 & 0,12 & 7,20 & 2,88 & 0,24 & 6,40 \\
\hline Cruz Alta & 5,6 & 0,84 & 0,05 & 0,30 & 2,40 & 0,96 & 0,17 & 1,84 \\
\hline Formigueiro & 6,1 & 0,90 & 0,09 & 0,11 & 4,00 & 1,28 & 0,06 & 2,16 \\
\hline
\end{tabular}

os métodos analíticos utilizados foram:

- Análise granulométrica: Método da pipeta.

- pH: relação solo: água igual a $1: 2,5$ (CATANI et alii, 1955).

- C\%: método de WALlLey e BLACK, modificado (Ralavolta e COURY, 1954).

- $\mathrm{PO}_{4}^{3-}$ sölüval: extração com solução de $\mathrm{H}_{2} \mathrm{SO}_{4} 0,05 \mathrm{~N}$ e ceterminação segundo CATANI et alii (1955).

- $\mathrm{K}^{+}$trocável: extração com solução de HNO ${ }_{3} 0,05$ M e determinação por fotometria de chama (CATANI et alii, 1955).

- $\mathrm{Ca}^{2+}$ trocāvel: extração com solução de RCl N e determinação por quelatometria. 
10.

- $\mathrm{Mg}^{2+}$ trocável: extração com 601 ução de KCl N e determinação por quelatometria.

- $\mathrm{Al}^{3+}$ trocável: extração com 601 ução de KCl N e titulação com $\mathrm{NaOH} 0,02 \mathrm{~N}$.

- H* tituláve1: extração com solução de acetato de cálcio normal e titulaçáo com NaOH $0,02 \mathrm{~N}$.

0 s materiais utilizados como adubos, foram o $\mathrm{CaCO}_{3} \mathrm{p}$. a. e torta de $180 \tilde{d}_{0}$ seca a $708 \mathrm{C}$ e triturada em micromoinho, com a seguinte composição em $\mathrm{N}, \mathrm{P}_{2} \mathrm{O}_{5}, \mathrm{~K}_{2} \mathrm{O}, \mathrm{CaO}$ e MgO (Tabela 3).

TABEla 3 - Teores de $\mathrm{N}, \mathrm{P}_{2} \mathrm{O}_{5}, \mathrm{~K}_{2} \mathrm{O}, \mathrm{CaO}$ e MgO da torta utilizada

\begin{tabular}{lc} 
Constituinte & Porcentagen \\
\hline $\mathrm{N}$ & 6,00 \\
$\mathrm{P}_{2} \mathrm{O}_{5}$ & 1,00 \\
$\mathrm{~K}_{2} \mathrm{O}$ & 1,26 \\
$\mathrm{CaO}$ & 0,12 \\
$\mathrm{MgO}$ & 0,46
\end{tabular}

0 arranjamento dos tratamentos foi o fatorial $2^{4}$ tendo sido o delineamento experimental inteiramente casualizado. As quantidades de $\mathrm{CaCO}_{3}$ p.a. empregadas foram baseadas no método do Al trocável utilizando o fator 1,5 e foram as se- 
guintes: $0,1,2$ e 3 vezes as necessárias para elininar o A1 trocävel das terras; as doses de torta de algodão foram correspa nondentes a $0,15,30$ e $45 \mathrm{t} / \mathrm{ha}$. Desse modo cara vaso recebeu as seguintes quantidades de adubo de acordo com o tratamento (Tabela 4)。Considerou-se a densidade anarente das terras igual a 1,5 e a profundidade de $20 \mathrm{~cm}$.

MABELA 4 Doses de $\mathrm{CaCO}_{3}$ p.a. empregadas por vasos segundo o tratamento

Solos Doses cuantidade de ruantidade de

\begin{tabular}{|c|c|c|c|}
\hline Três Iunicĩpios & $\begin{array}{l}1 \\
2 \\
3 \\
4\end{array}$ & $\begin{array}{r}0 \\
520 \\
1.040 \\
1.560\end{array}$ & $\begin{array}{r}0 \\
5 \\
10 \\
15\end{array}$ \\
\hline $\mathrm{Pau} \mathrm{D}^{\prime} \mathrm{A} 1 \mathrm{ho}$ & $\begin{array}{l}1 \\
2 \\
3 \\
4\end{array}$ & $\begin{array}{r}0 \\
15 \\
30 \\
45\end{array}$ & $\begin{array}{r}0 \\
5 \\
10 \\
15\end{array}$ \\
\hline Iracena & $\begin{array}{l}1 \\
2 \\
3 \\
4\end{array}$ & $\begin{array}{r}0 \\
120 \\
240 \\
360\end{array}$ & $\begin{array}{r}0 \\
5 \\
10 \\
15\end{array}$ \\
\hline Cruz Alta & $\begin{array}{l}1 \\
2 \\
3 \\
4\end{array}$ & $\begin{array}{r}0 \\
85 \\
170 \\
255\end{array}$ & $\begin{array}{r}0 \\
5 \\
10 \\
15\end{array}$ \\
\hline Formisueiro & $\begin{array}{l}1 \\
2 \\
3 \\
4\end{array}$ & $\begin{array}{r}0 \\
30 \\
60 \\
90\end{array}$ & $\begin{array}{r}0 \\
10 \\
15\end{array}$ \\
\hline
\end{tabular}




\subsection{Conciução do Experimento}

Porções de $1 \mathrm{~kg}$ de T.F.S.A. foram intimamente misturadas com os adubos de acordo como tratamento, passadas paravasos (*) incubadas durante 30 dias sob condições de laboratório, e permane cendo ümidas (aproximadamente $50 \%$ da capacidade de retenção de umi dade). Cada tratamento foi repetido quatro vezes.

Após o período de incubação as terras foram secas ao ar, sobre 1 âminas de plástico, destorroadas e analisadas.

As determinações efecuadas foram: $p h, A^{3+}$ trocáve 1 e $\xi^{+}$titulàvel.

$0 \mathrm{pH}, \mathrm{OAl}^{3+}$ trocävel e $\mathrm{H}^{+}$titulävel foram determinados pelos métodos citados em 3.1 .

os resultados obtidos foram submetidos à análise estatís tica.

1 1 Latas de öleo de motor ce automövel pintadas internamente com Heutrol 45 e externamente com a tinta Alumilak 9.800 da Cia. Ipiranga. 
4.1 - Efeitos do $\mathrm{CaCO}_{3}$ sobre o pH das Terras

Os efeitos do $\mathrm{CaCO}_{3}$ sobre o pH das terras aparecem na Tabela 5. A Figura 1 representa esses resultados.

Observarse que a tendência geral do $\mathrm{CaCO}_{3}$ foi a de elevar o pl das terras, como era de se esperar, embora apenas no caso da sêrie Três Municípios o seu efeito tenha sido significativo entre tratamentos. $\quad 0$ fato do carbonato não ter afetado signi ficativamente o pli das outras terras talvez se deva às peouenas quantidades empregadas, consequência do baixo teor de Al ${ }^{3+}$ trocá vel das mesmas (Tabela 2). 
TABELA 5 Efeitos do $\mathrm{CaCO}_{3}$ sobre o pH das terras

\begin{tabular}{cccccc}
\hline Doses de & & \multicolumn{2}{c}{ Solos } & \\
$\mathrm{CaCO}_{3}$ & Três Municípios & Pau D Alho & Iracema & Cruz Alta & Formigueiro \\
1 & 4,96 & 5,88 & 5,63 & 6,01 & 5,77 \\
2 & 5,01 & 5,92 & 5,70 & 6,23 & 5,89 \\
3 & 5,28 & 6,01 & 5,80 & 6,18 & 5,90 \\
4 & 5,39 & 5,91 & 5,69 & 6,19 & 5,98 \\
& D.M.S. Tukey a $5 \%=0,28$ & & \\
& & C. V. $=4,53 \%$ & \\
\hline
\end{tabular}

Fisse resultado, de certa forma, não constitui surpresa em vista do que foi exposto em 2.1 .

Notarse que na sërie Três Municípios, com ple inicial mais baixo, maior teor de argila e menor teor de areia, com poder tampão, portanto, dos mais elevados entre as terras utilizadas nem a dose maior de $\mathrm{CaCO}_{3}$ foi suficiente para elevar o pll ao valor desejado. 


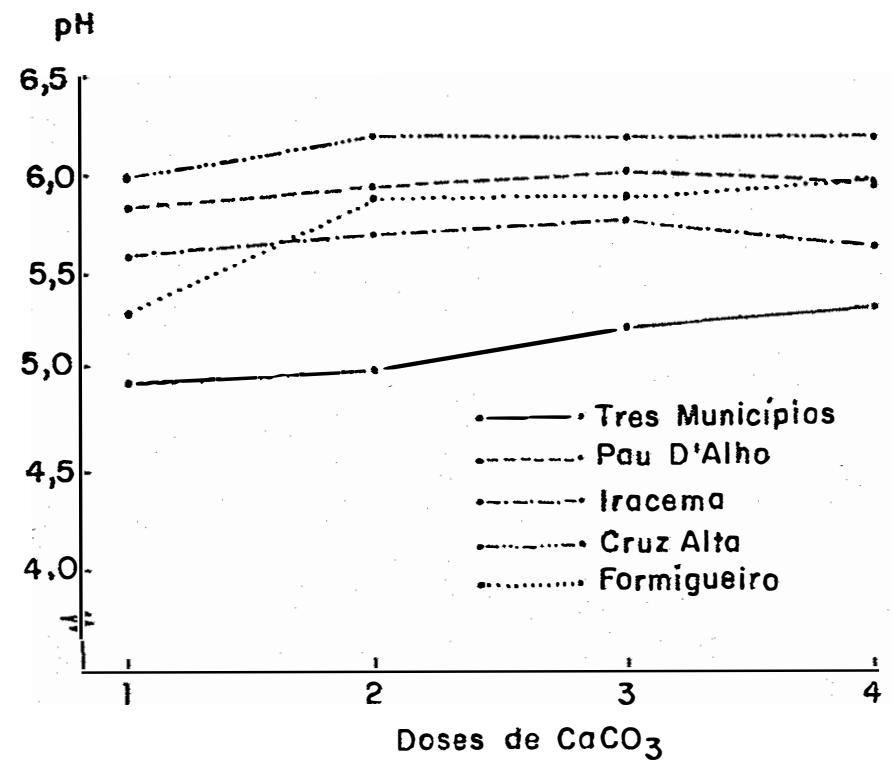

Fig. 1 - Efeito do $\mathrm{CaCO}_{3}$ sobre os pHs das terras 
4.2 - Efeitos da Matéria Orgânica sobre o pH das Terras

A influência da matéria orgânica sobre o pll aparece sintetizada na Tabela 6 , a título de ilustração, na Figura 2

TABELA - É - Efeitos da matéria orgânica sobre o pH das terras

\begin{tabular}{cccccc}
\hline $\begin{array}{l}\text { Doses de } \\
\text { matéria } \\
\text { orgânica }\end{array}$ & Três Municípios & Pau D Alho & Iracema & Cruz Alta & Formigueiro \\
\hline 1 & 5,33 & 5,81 & 5,29 & 6,13 & 5,82 \\
2 & 4,90 & 5,89 & 5,52 & 6,17 & 5,67 \\
3 & 5,03 & 5,92 & 5,89 & 6,18 & 5,98 \\
4 & 5,38 & 6,10 & 6,12 & 6,13 & 6,03 \\
\hline & D.M.S. Tukey a $5 \%=0,28$ & \\
& C. V. $=4,53$
\end{tabular}

0s dados da Tabela 6 representados na Figura 2 revelam que a tendência geral da matéria orgânica foi a de elevar o pH das terras. Entretanto, dentro dessa tendência geral, há algumas excessões:

a - Dentro da série Três Municípios: a dose 1 da matéria orgânica superou as doses 2 e 3 , não diferindo significativa mente da dose 4 : 
b - Dentro da série Pau D'Alho: a dose 1 foi superada apenas pe 1 a $4:$

c - Dentro da sērie Iracema: as doses 1 e 2 de matéria orgânica não apresentaram resultados estatisticamente diferentes entresi, o mesmo acontecendo com as doses 3 e $4 \%$ estas, contudo superaram as doses 1 e 2 :

d - Dentro da série Cruz Alta: não houve alteração significativa do pll:

e - Dentro da série Formigueiro: não houve efeito significativo entre as doses 1 e 2 , o mesmo acontecendo entre as 3 e 4 : estas, entretanto, apresentaram resultados superiores à dose 2

Tentativamente pode-se explicar do seguinte modo a tendência da matéria orgânica de elevar o pH do solo:

Em primeiro lugar, tratando-se de experimento de curta duração, ê possível que ao término do período de incubação grande parte do $\mathbb{N}$ da torta estivesse na forma amoniacal, o que teria ele vado o pH ; essa explicação, de certa forma, encontra apoio no trabalho de MELLO et alii (1977) que encontraram grande quantidade de $\mathrm{N}-\mathrm{NH}_{4}^{+}$em solos de cerrado após incubação com torta de algodão, come sem $\mathrm{CaCO}_{3}$, durante 30 dias.

A segunda hipótese seria a seguinte: no processo de de composição da torta formamose numerosos radicais orgânicos com cargas negativas e que são, portanto, capazes de reter $\mathrm{k}^{+} \mathrm{da}$ solu ção do solo, com elevação consequente do pH. 
18

A terceira hipótese seria a de que os cátions da torta, 1 ivres pela decomposição desta, atuariam no sentido de aumentar o pH das terras.

os resultados obtidos com relação aos efeitos da maté ria orgânica sobre o pl do solo estão de acordo com värias observações, conforme consta no item 2.2 . 


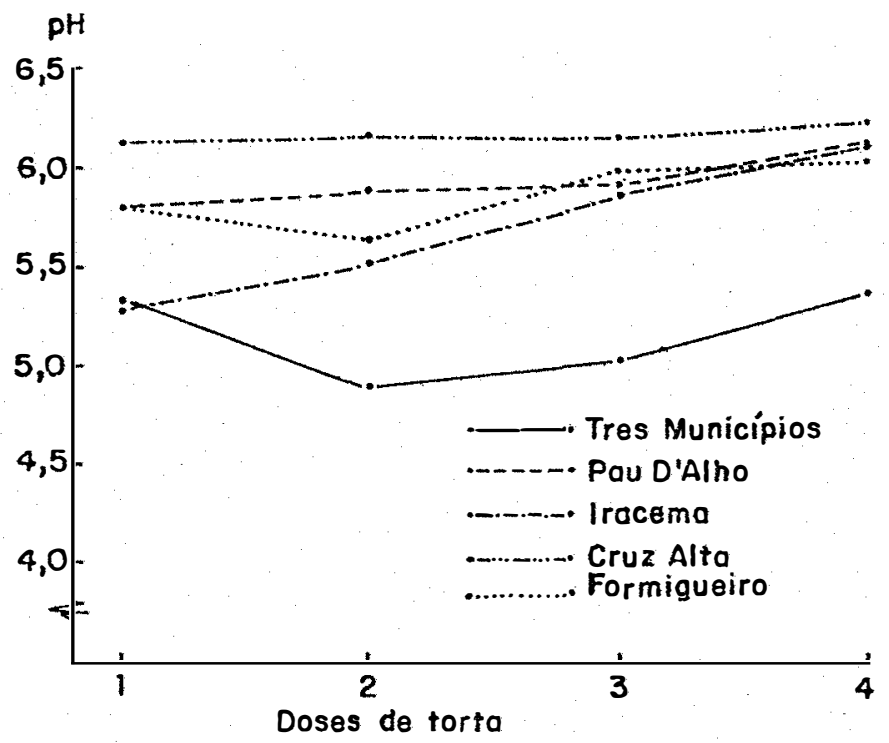

Fig. 2 - Efeitos da matēria orgânica sobre os pHs das terras 
4.3 - Efeito sobre o pli do $\mathrm{CaCO}_{3}$ Tentro de latéria Orcânica e da Matéria Orôanica Dentro de $\mathrm{CaCO}_{3}$

Pode-se observar pelos dados da Tabela 7 , que a terdencia do $\mathrm{CaCO}_{3}$ de elevar o Dll das terras só anarece de modo signifi cativo na ausência de matéria orộnica.

TABELA 7 - Efeitos sobre o pH do $\mathrm{CaCO}_{3}$ dentro de matéria orgânica e da matéria orgânica dentro de $\mathrm{CaCO}_{3}$

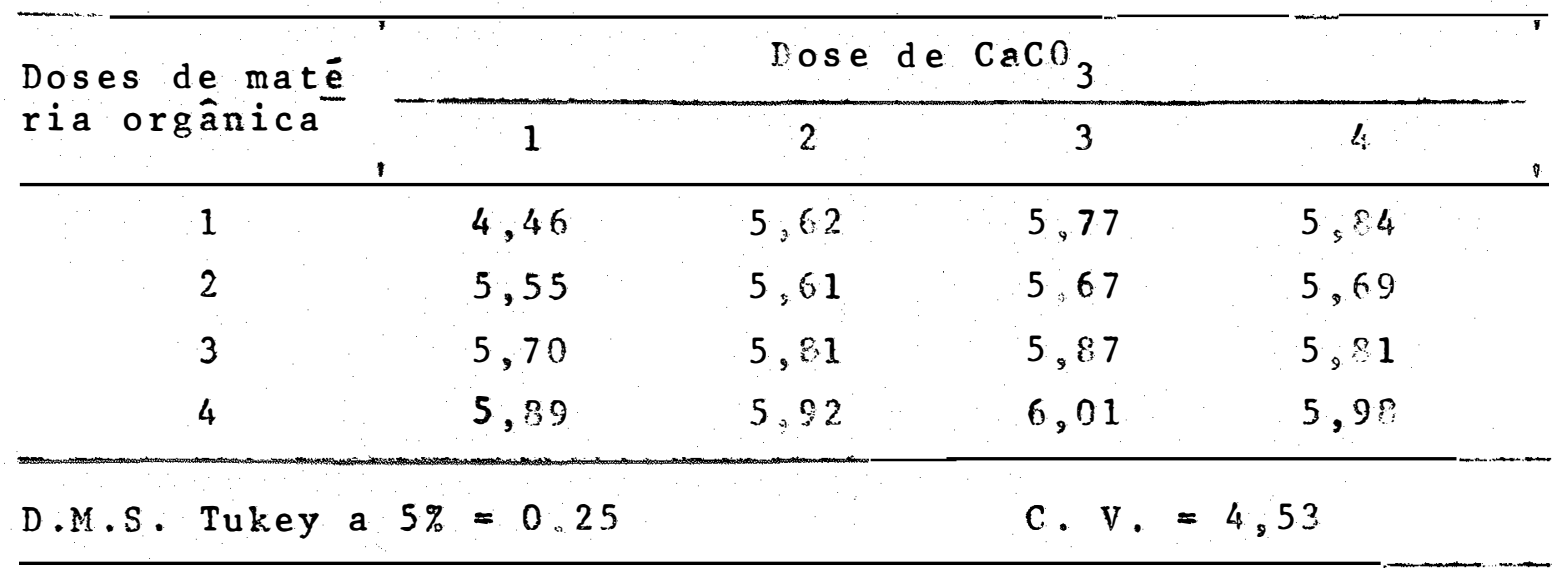

Da mesma forna em todos os niveis empregados de $\mathrm{CaCO}_{3}$ o efeito geral da torta de alrodão foi o de elevar o pry, tendo ocorrido diferenças significativas dentro de todas as doses de carbonato, exceto dentro da dose 4 .

As Figuras 3 e 4 ilustram o que ocorreu.

De um modo geral o ereito do $\mathrm{CaCO}_{3}$ ficou prejudicado

devido à pequenas quantidades utilizadas do mesmo e, possivelmen te, pelo aumento do poder tampão que a matéria orgânica confere aos solos. Daí, talvez o $\mathrm{CaCO}_{3}$ só ter produzido diferenças sig. nificativas quando na ausência de torta de algodão. 


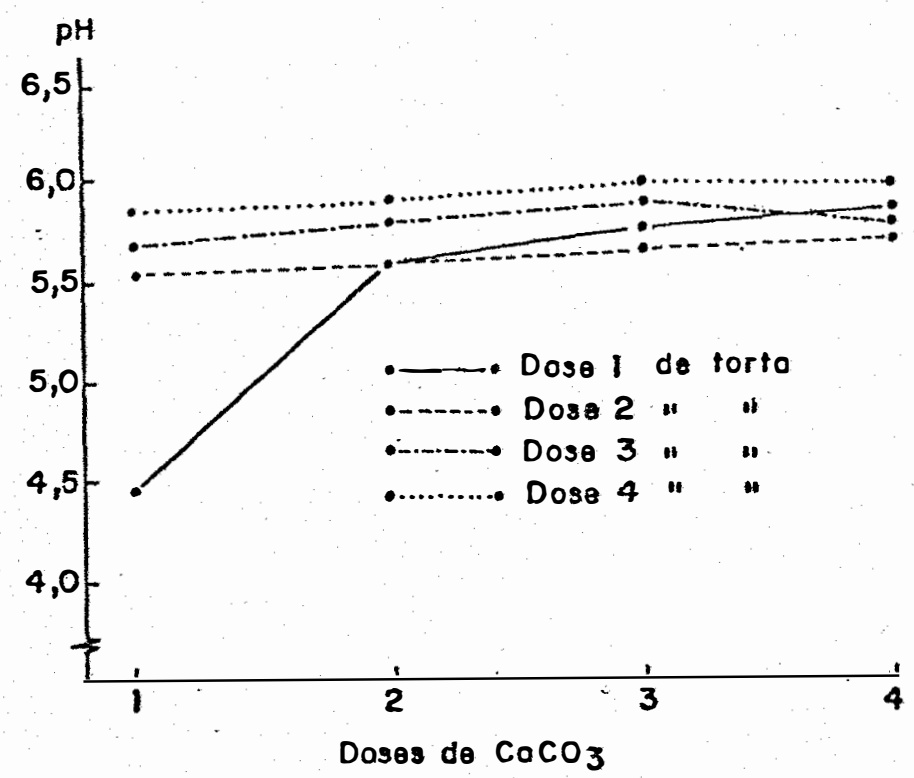

Fig. 3 - Efeitos do $\mathrm{CaCO}_{3}$ sobre o pH, dentro de matēria orgânica

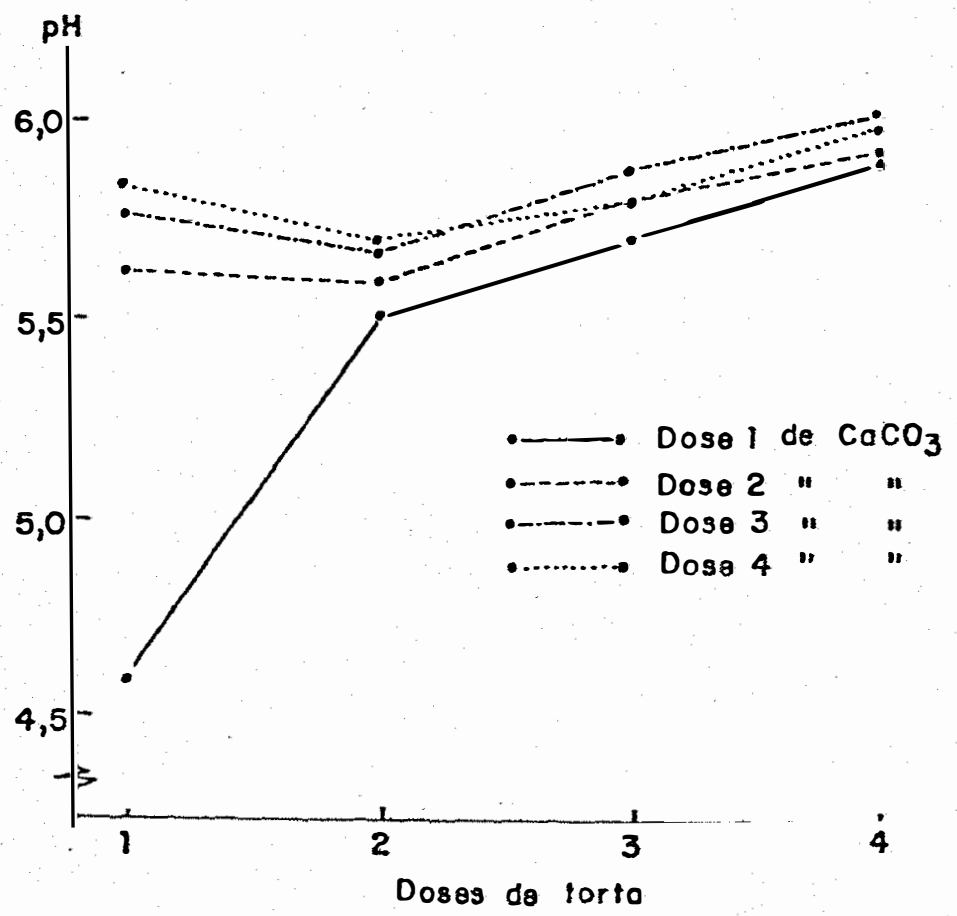

Fig. 4 - Efeitos da matēria orgãnica sobre o $\mathrm{pH}$, dentro de $\mathrm{CaCO}_{3}$ 
4.4 Efeitos do $\mathrm{CaCO}_{3}$ sobre os Teores de $\mathrm{Al}^{3+}$ trocável das Terras

Os resultados obtidos aparecem na Tabela e são ilustrados pela figura 5 .

TABELA E - Efeitos do $\mathrm{CaCO}_{3}$ sobre o teor de $\mathrm{Al}^{3+}$ trocâvel das terras

\begin{tabular}{cccccc}
\hline Doses de & \multicolumn{5}{c}{ Solos } \\
\cline { 2 - 6 } $\mathrm{CaCO}_{3}$ & Três Punicínios & Pau D Alho & Iracema & Cruz Alta & Formigueiro \\
\hline 1 & 0,73 & 0,17 & 0,24 & 0,21 & 0,14 \\
2 & 0,50 & 0,16 & 0,21 & 0,20 & 0,14 \\
3 & 0,32 & 0,16 & 0,20 & 0,20 & 0,13 \\
4 & 0,22 & 0,17 & 0,19 & 0,20 & 0,16 \\
\hline
\end{tabular}
D.RI.S. Tuley a $5 \%=0,04$
C. V. $=16,05 \%$

Verifica-se que as diferentes doses de $\mathrm{CaCO}_{3}$ tiverat efeitos significativos, apenas no solo Três Municípios no Iracema, somente a dose 4 diferiu estatisticamente da dose 1 , não diferindo, porëm, das demais. Igualmente, neste solo: os tratamentos 1,2 e 3 apresentaran o mesmo resultado.

Nos demais solos, não houve diferencas singificativas

entre os tratamentos, resultado que o autor não possui argumentos convincentes para explicar. Forẻm, a não eliminação total do Al trocável está de acordo com sERvin (1971) e PITTA (1974) e tal vez possa ser atribuído ao excessivo rión na titulação final. 
23.

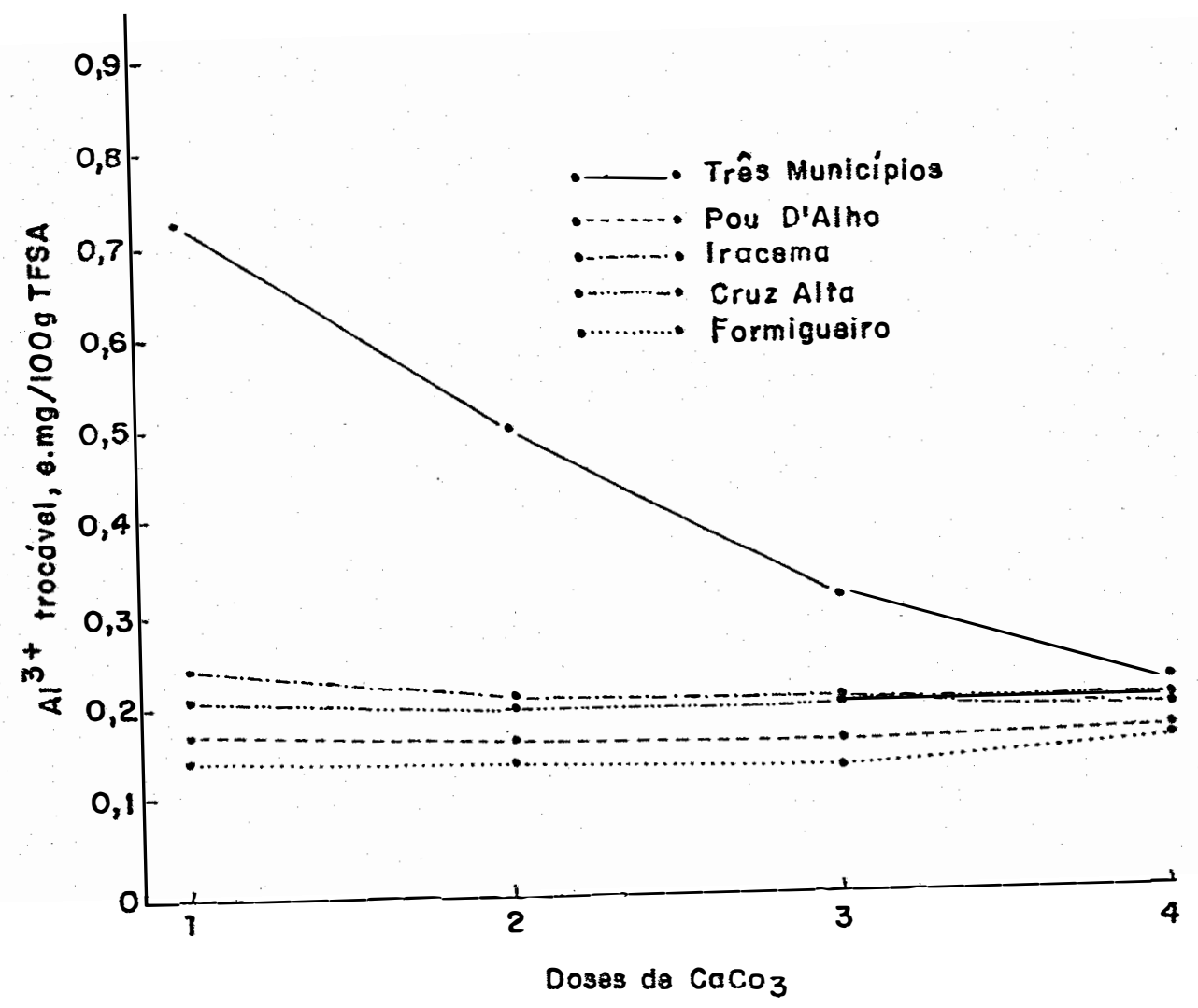

Fig. 5 - Efeitos do $\mathrm{CaCO}_{3}$ sobre os teores de $\mathrm{Al}^{3+}$ trocāvel das terras 
4.5 Efeitos da atêria Orgânica sobre o Teor de $\mathrm{Al}^{3+}$ Trocáve 1 das Terras

os resultados obtidos a este respeito são apresentados na Tabela 9.

TAPELA 9 - Efeitos da motéria orgânica sobre o teor de $\mathrm{Al}^{3+}$ trocāvel das terras

\begin{tabular}{cccccc}
\hline $\begin{array}{l}\text { Doses de } \\
\text { matéria } \\
\text { orrânica }\end{array}$ & Três Municínios & Pau $D^{0}$ Alho & Iracema & Cruz Alta & Formigueiro \\
\hline 1 & 0,45 & 0,09 & 0,20 & 0,15 & 0,11 \\
2 & 0,52 & 0,14 & 0,19 & 0,19 & 0,12 \\
3 & 0,44 & 0,18 & 0,20 & 0,21 & 0,15 \\
4 & 0,37 & 0,24 & 0,24 & 0,25 & 0,19 \\
\hline
\end{tabular}

D. I. S. Tukey a $5 \%=0,04$

C. . V. $=16,95 \%$

Como a tendência geral da matéria orgânica foi a de ele var o pla das terras, era de se supor aue o inverso ocorresse com o teor de $\mathrm{Al}^{3+}$ trocáve 1 .

Os nümeros da Tabela 9 mostram aue:

a - na série Três Prunicípios na dose 2 de natéria or rânica apare ceu o maior teor de Al trocável e na dose 4, o menor. As doses 1 e 3 apresentaram efeitos intermediärios: sem diferirem entre si. 
b - llas sēries Pau D'Alho, Cruz Alta e Formigueiro houve nítida tendência da torta aumentar o teor de $A 1^{3+}$ trocável das terras, embora nem sempre as diferenças entre tratamentos te Ih am sido significativas.

c - Ma série Iracema, apenas a dose 4 de torta mostrou tendência a e elevar o teor de $\mathbb{A}^{3+}$ trocável: esta dose entretanto, pro duziu resultado que diferiu apenas do apresentado pela dose 2 as doses 1,2 e 3 não anresentaram resultados diferen tes, estatisticamente, entre si.

os resultados obtidos não são explicados pelos pHs das terras (CATANI e ALONSO, 1969 ? MELLO, não publicado) dos diversos tratamentos contidos na Tabela 6 , nem pelo Al da torta e não concordam com os resultados obtdoos por pello et ali i (não publicado,b). Contudo, em trabalho semelhante, zAGo (não publicado). utilizando dois Latossolos do Fstado de São Paulo declararar que "os dados obtidos en relação ao $A 1^{3+}$ trocável não permitem uma conclusão geral", o quê estā de acordo com o obtido nesta disser.. tação.

A Figura 6 sintetiza os resultados obtidos. 


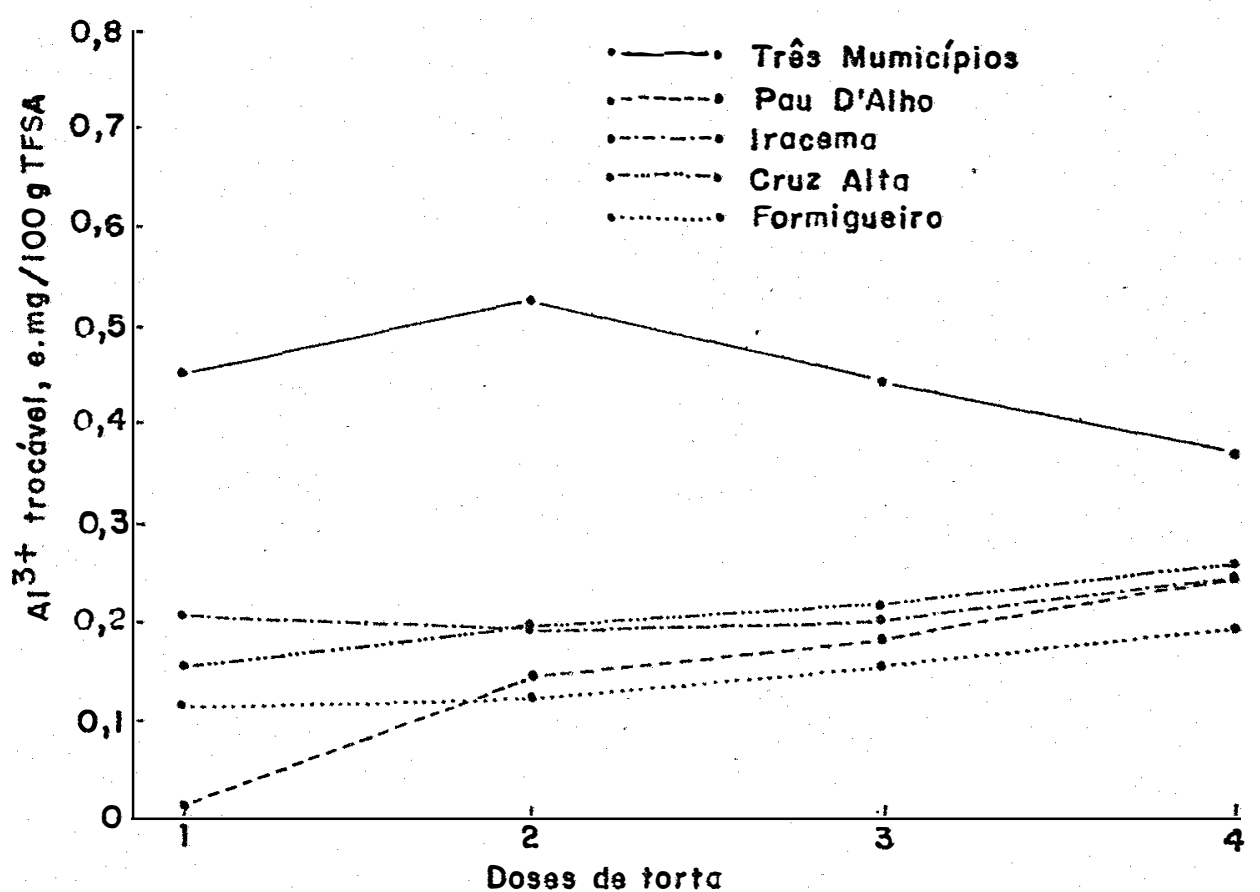

Fig. 6 - Efeitos da matēria orgânica sobre os teores de $\mathrm{Al}^{3+}$ trocāvel das terras 


\section{6 - Efeitos sobre os Teores de $\mathrm{Al}$ trocável do $\mathrm{CaCO}_{3}$ Dentro de Matéria Orrânica e da latéria Oroânica Dentro de $\mathrm{CaCO}_{3}$}

os resultados obtidos a este respeito se acham na Tabe 1a 10. Aparecem, tambëm, com finalidade ilustrativa nas Figu ras 7 e $\$$

TABELA 10 Efeitos do $\mathrm{CaCO}_{3}$ dentro de matéria orgânica e da matéria orônica dentro de $\mathrm{CaCO}_{3}$ sobre os teores de Al trocável

\begin{tabular}{|c|c|c|c|c|}
\hline \multirow{2}{*}{$\begin{array}{c}\text { Doses de Paté- } \\
\text { ria orpanica }\end{array}$} & \multicolumn{4}{|c|}{ Doses de $\mathrm{CaCO}_{3}$} \\
\hline & 1 & 2 & 3 & 4 \\
\hline 1 & 0,32 & 0,18 & 0,15 & 0,14 \\
\hline 2 & 0,32 & 0,24 & 0,20 & 0.17 \\
\hline 3 & 0,20 & 0,26 & 0,20 & 0,20 \\
\hline 4 & 0,28 & 027 & 0,25 & 0,24 \\
\hline
\end{tabular}

D.M. S. Tukey a $5 \%=0,04$

C. V. $=16,95 \%$

Os dados da Tabela 10 revelam que em todas as doses de matéria orgânica o efeito do $\mathrm{CaCO}_{3}$ foi o de reduzir o teor de Al trocável, embora nem sempre as diferenças entre doses de $\mathrm{CaCO}_{3}$ tenham sido significativas, talvez devido às nequenas quantidades usadas de carbonato. Esta explicação contudo, possivelmente não 
é correta pois mesmo sendo pequenas as doses de caco 3 utilizadas elas foram suficientes ou em excesso para precipitar todo o A1 trocàvel.

quanto aos efeitos de matéria orgânica dentro de $\mathrm{CaCO}_{3}$ constata-se que nas doses 2,3 e 4 de $\mathrm{CaCO}_{3}$ a influência da tor ta de algodão foi a de elevar o teor de Al trocável, embora as di ferencas dos efeitos entre doses deste fertilizante nem sempe te nham sido significativas. Dentro da dose 1 de $\mathrm{CaCO}_{3}$ (ausência de $\left(\mathrm{CaCO}_{3}\right)$, a matéria orgânica, não afetou significativamente o teor de Al trocävel.

Estes resultados são de explicacão difícil, conforme jä foi comentado no item 4.5 


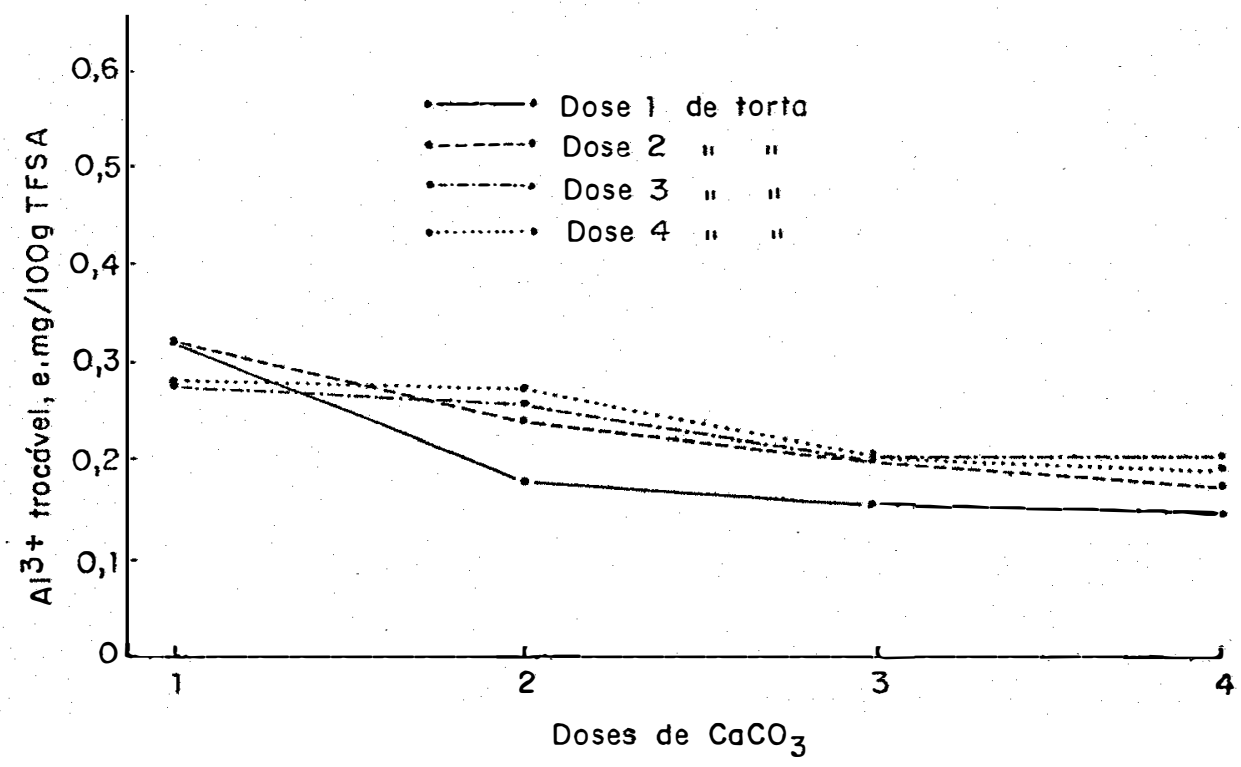

Fig. 7 - Efeitos do $\mathrm{CaCO}_{3}$ sobre o $\mathrm{Al}^{3+}$ trocävel, dentro de matéría orgânica

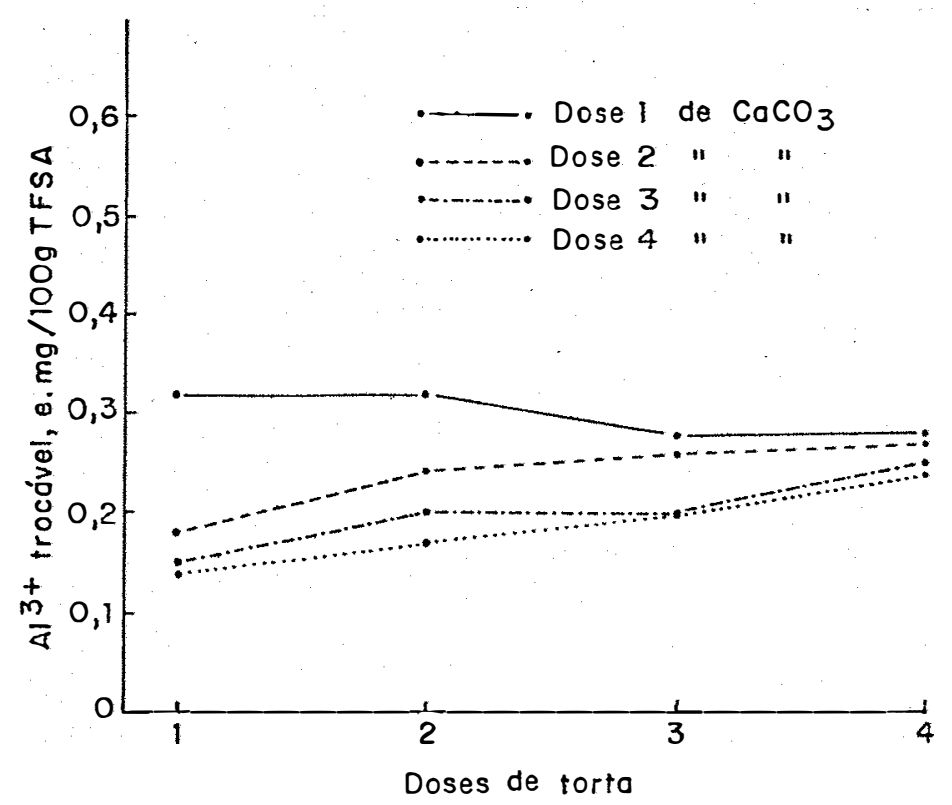

Fig. 8 - Efeitos da matēria orgânica sobre o $\mathrm{Al}^{3+}$ trocāvel, dentro de $\mathrm{CaCO}_{3}$ 
4.7 - Efeitos do $\mathrm{CaCO}_{3}$ sobre os Teores de $\mathrm{H}$ Total das Terras

Os dados apresentados na Tabela 11 resumem os resulta dos obtidos. A Figura 9 os ilustra.

TABELA 11 - Efeitos do $\mathrm{CaCO}_{3}$ sobre os teores de $y$ total das terras

\begin{tabular}{cccccc}
\hline $\begin{array}{c}\text { Doses de } \\
\mathrm{CaCO}_{3}\end{array}$ & Três Municínios & Pau D'Alho & Iracema & Cruz Alta & Fornigueiro \\
\cline { 2 - 6 } & 6,68 & 3,64 & 7,74 & 2,58 & 2,14 \\
2 & 6,05 & 3,60 & 7,23 & 2,53 & 2,10 \\
3 & 5,46 & 3,61 & 7,17 & 2,51 & 2,16 \\
4 & 4,69 & 3,69 & 7,13 & 2,17 & 2,45 \\
\hline D.H.S. Tukey a $5 \%=0,61$ & & C. V. $=12,73$ & \\
\hline
\end{tabular}

Os resultados observados na sêrie Três lunicípios, na qual as doses crescentes de $\mathrm{CaCO}_{3}$ reduziram significativamente os teores de ll total e na sërie Iracema, embora nesta. não tenba ocorrido diferenças significativas são coerentes com o que se espe rava e concordam com outros autores (SERVIN, 1971: DITTA, 1974).

0 que aconteceu nas sēries Pau n'Alho e Tormigueiro é dificil de ser explicado: possivelmente se deve a erros experi mentais. Deve-se notar, entretanto, que apesar da tendência do efeito quadrático, não houve diferenças significativas entre tratamentos. 


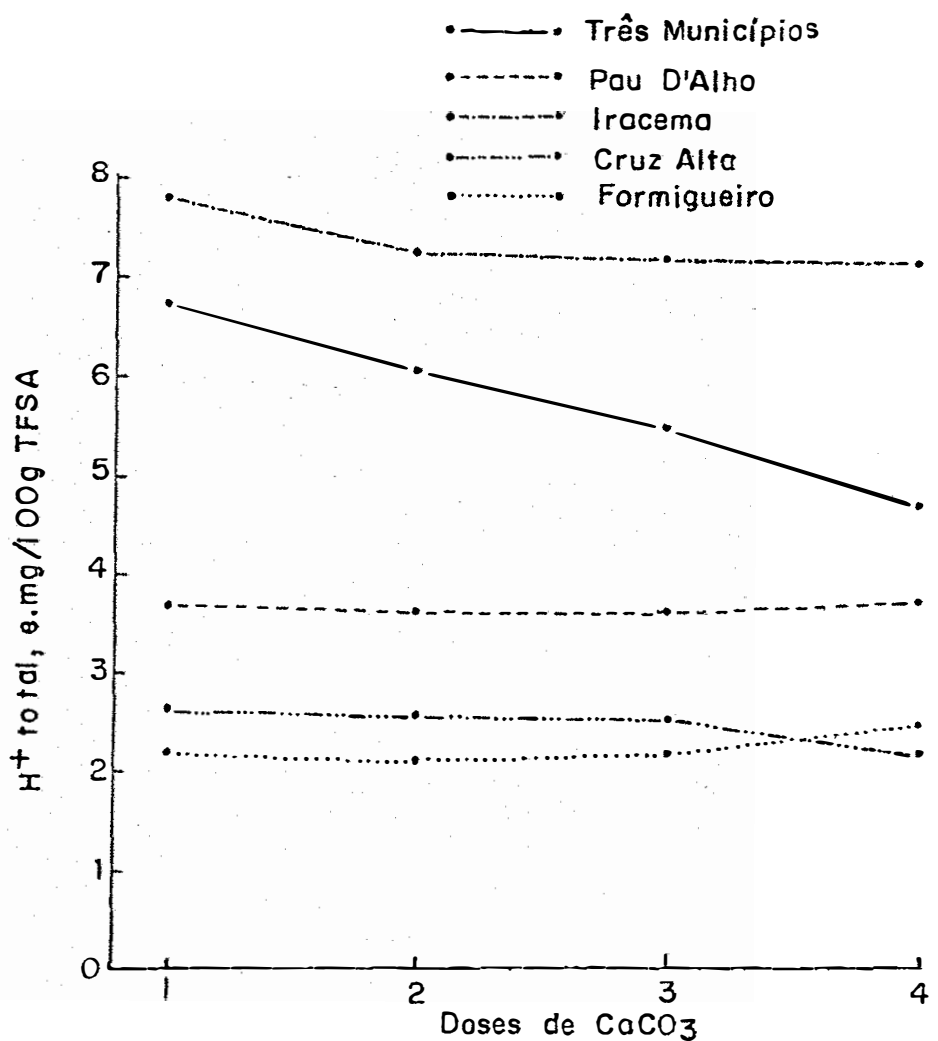

Fig. 9 - Efeitos do $\mathrm{CaCO}_{3}$ sobre os teores de $\mathrm{H}^{+}$das terras 
4.8 Efeitos da Matëria Orgânica sobre os Teores de Il Total. aas Terras

Os elementos da Tabela 12 revelam os efeitos que a torta de algodão exerceu sobre os teores de $\mathrm{y}^{+}$total das terras. A Figura 10 ilustra esses resultados.

TABELA 12. Efeitos da matéria orgânica sobre os teores de HI $^{+}$ total das terras

\begin{tabular}{ccccccc}
\hline $\begin{array}{c}\text { Doses de } \\
\text { Matéria } \\
\text { Orgânica }\end{array}$ & Três Municípios & Pau D Alho & Iracema & Cruz Alta & Formigueiro \\
\hline 1 & 5,59 & 3,86 & 7,84 & 2,43 & 2,17 \\
2 & 5,99 & 3,66 & 7,58 & 2,38 & 2,28 \\
3 & 5,92 & 3,62 & 7,07 & 2,47 & 2,13 \\
4 & 5,36 & 3,40 & 6,77 & 2,51 & 2,26 \\
\hline
\end{tabular}

D. M. S. Tukey a $5 \%=0,61$

C. V. $=12,73 \%$

Nota-se que nas séries Pau D'Alho e Iracema a matéria orgânica tendeu a reduzir a acidez total, embora diferenças siga nificativas só sejam encontradas na série Iracema, onde as doses 3 e 4 de torta superaram a dose 1 e a dose 4 superou a 2 . Estes resultados estão de acordo com os obtidos por PAZ et ali (1966) e por ZAGO et alii (não publicado).

Nas demais séries de solos tal tendência não foi obser vada não havendo diferenças significativas entre tratamentos, ex ceto na Três Municipios na cual a dose 4 de torta superou esta tisticamente a dose 2 , resultado inesperado e em desacordo com a I iteratura citada. 


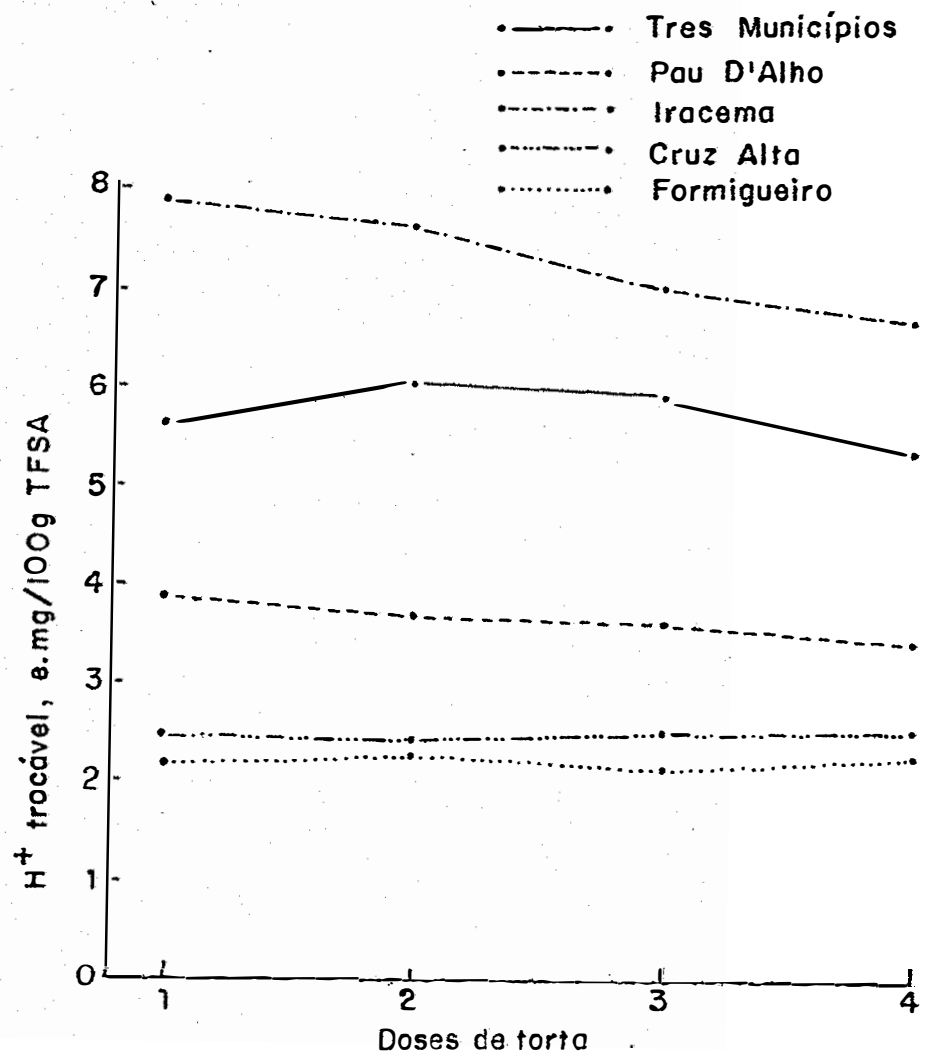

Fig. 10 - Efeitos da matéria orgânica sobre os teores de $\mathrm{H}^{+}$das terras 


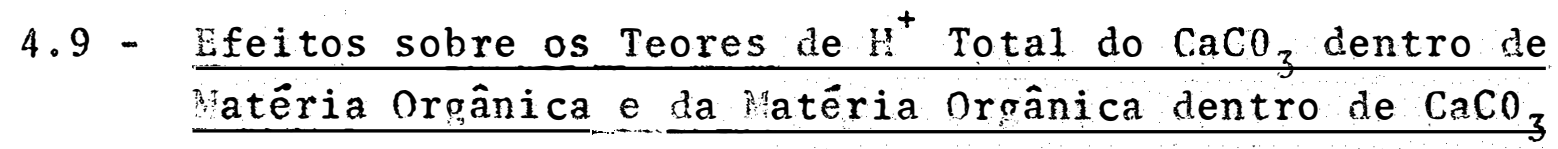

os resultados obtidos se acham resumidos na Tabela 13

e representados nas Figuras 11 e 12 .

TABELA 13 - Efeitos do $\mathrm{CaCO}_{3}$ dentro de matéria orgânica e da matéria orgânica dentro de $\mathrm{CaCO}_{3}$ sobre os teores de $y^{+}$trocäve 1

\begin{tabular}{ccccc}
\hline $\begin{array}{c}\text { Doses de Laté- } \\
\text { ria Organica }\end{array}$ & \multicolumn{4}{c}{ Doses de $\mathrm{CaCO}_{3}$} \\
\hline 1 & 1 & 2 & 3 & 4 \\
\hline 2 & 4,77 & 4,36 & 4,33 & 4,06 \\
3 & 4,64 & 4,47 & 4,35 & 4,07 \\
4 & 4,55 & 4,25 & 4,12 & 4,06 \\
& 4,27 & 4,14 & 4,39 & 4,31 \\
\hline
\end{tabular}

D. M. S. Tukey a $5 \%=0,52$

C. $V_{0}=12,73 \%$

Dentro das quatro doses de matéria orgânica hä tendência geral do $\mathrm{CaCO}_{3}$ de reduzir os teores de $\mathrm{H}^{+}$total Entretanto. diferenças estatisticamente siğnificativas só existem nos seguintes casos:

a - Dentro da dose 1 de matēria orgânica: entre as doses 1 e 4 de $\mathrm{CaCO}_{3}$ 
b - Dentro da dose 2 de matéria orgânica: entre as doses 1 e 4 de $\mathrm{CaCO}_{3}$.

Dentro das doses 3 e 4 de matéria orgânica não hà diferenças significativas entre as doses de $\mathrm{CaCO}_{3}$.

os resultados observados estão de acordo com o que se conbece a respeito do $\mathrm{CaCO}_{3}$ sobre a acidez total. A ausência de diferenças significativas dentro das doses 3 e 4 de matéria orgânica pode ser atribuída às pequenas doses de $\mathrm{CaCO}_{3}$ empregadas è elevação do poder tampão das terras causado pelas doses mais elevadas de torta de algodão.

No que se refere aos efeitos da matéria orgânica a tendência geral da mesma foi a de reduzir os teores de $\mathrm{H}^{+}$total embo ra não tenha ocorrido diferenças significativas dentro de doses de $\mathrm{CaCO}_{3}$. Esses resultados concordam com os obtidos por ZAGo et alii (não publicado) es de certo modo, também com os de PAZ et alii (1977).

Nota-se que, na dose $4 \mathrm{de} \mathrm{CaCO}_{3}$ a maior dose empregada de torta elevou a acidez total das terras embora de modo não sig nificativo, estatisticamente. 


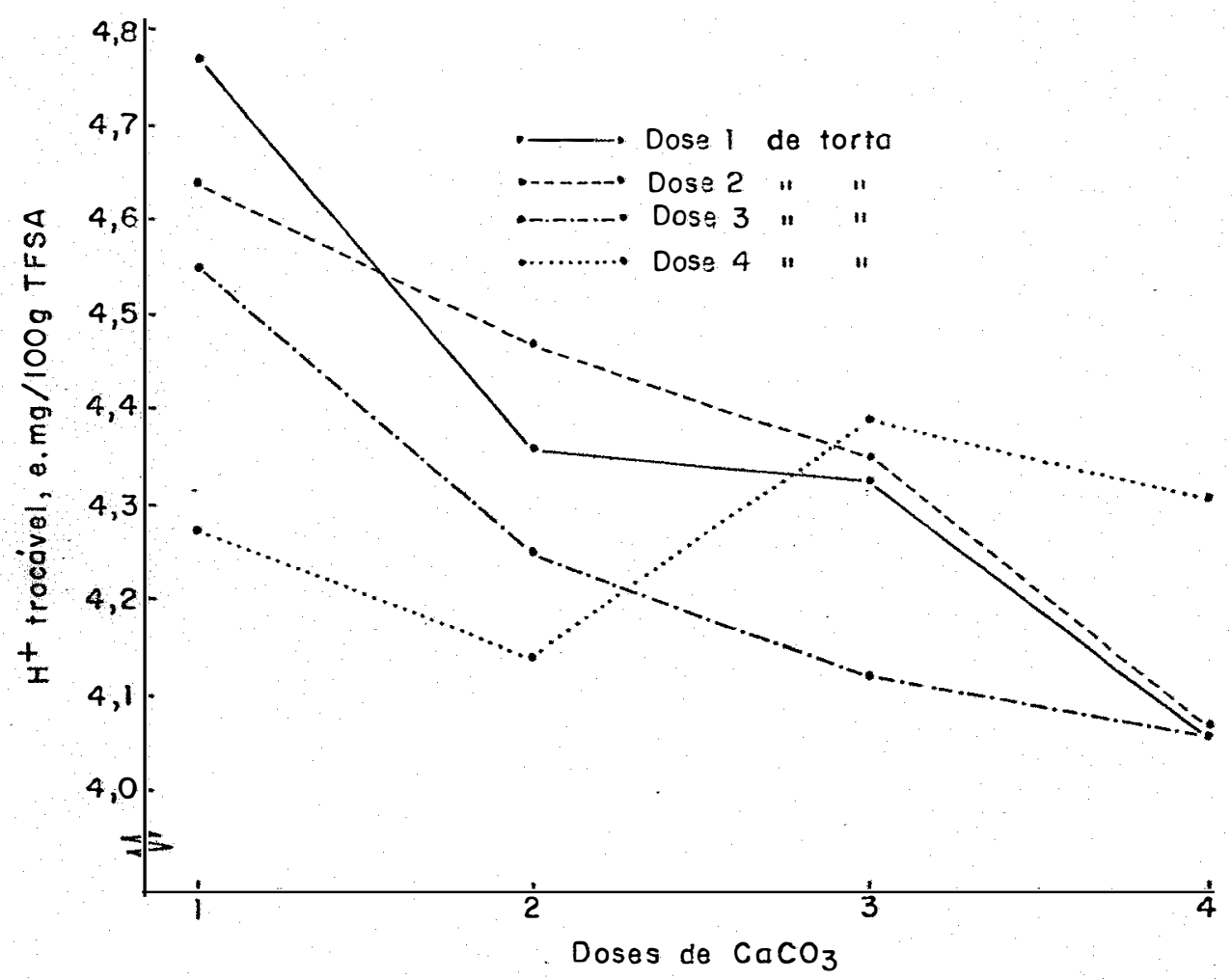

Fig. 11 - Efeitos do $\mathrm{CaCO}_{3}$ sobre os teores de $\mathrm{H}^{+}$ das terras dentro de matēria orgânica

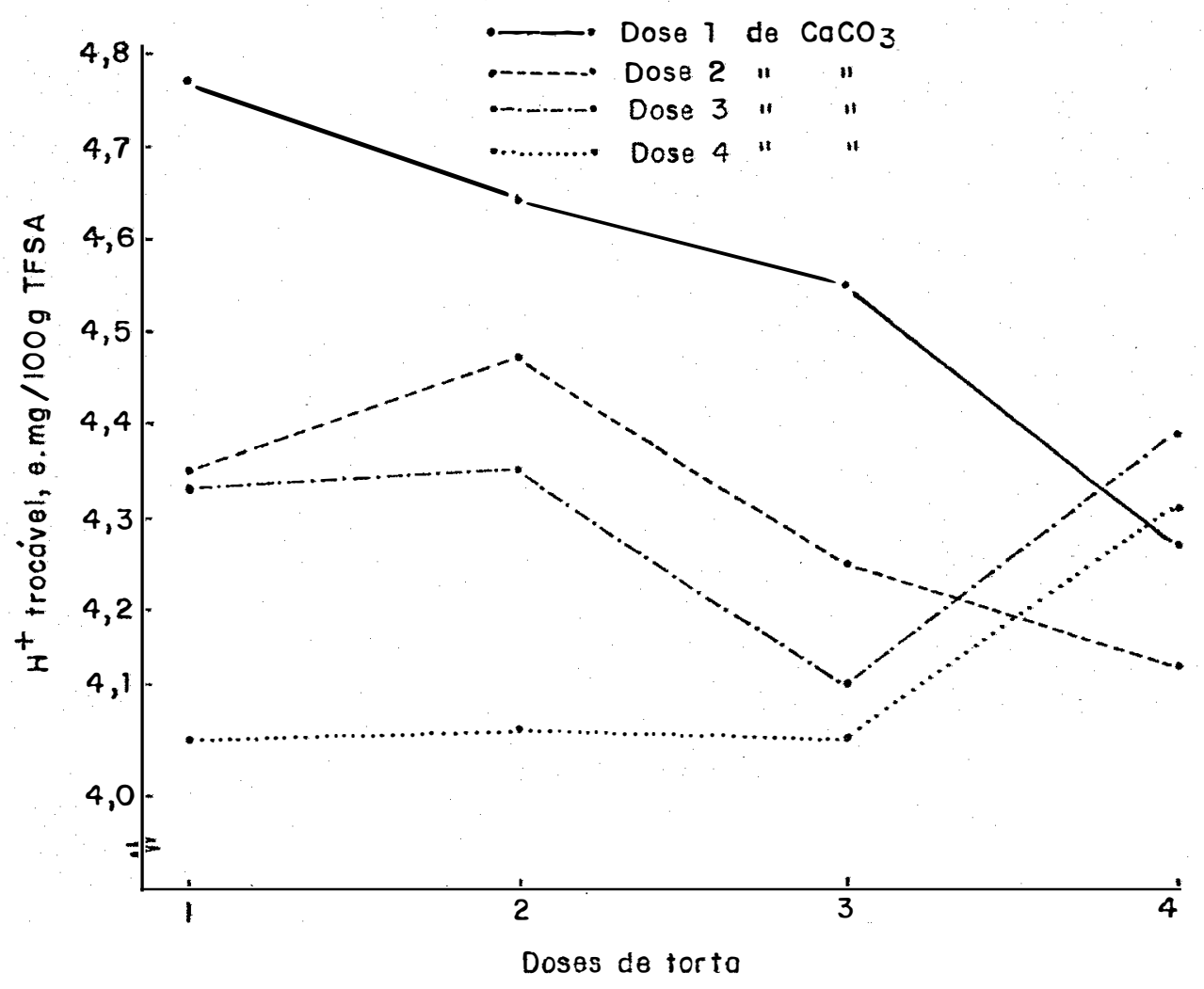

Fig. 12 - Efeitos da matéria orgãnica sobre os teo res das terras, dentro de $\mathrm{CaCO}_{3}$ 
As princinais conclusões alcançadas podem ser resumidas da seguinte maneira:

a - o método do Al trocável recomendou quantidades pequenas de calcārio, insuficientes para eliminar totalmente o Al trocável das terras e só na ausência de matéria orgânica elevou eficamente o py, sem exercer efeitos anreciáveis sobre a acidez total.

b - A matéria orgânica apresentou tendência geral de elevar o $n H$ das terras, tendo sido dubio os seus efeitos sobre os teores de Al trocável e H total. 
This dissertation deals with a factorial experiment, $2^{4}$ $\mathrm{CaCO}_{3} \mathrm{x}$ organic mattex in the form of cotton seed meal.

The quantities of $\mathrm{CaCO}_{3}$ were calculated by the exchan geable Al method, using, the 1.5 factor. They were the following: $0,1,2$ and $?$ times the amount needed to eliminate the exchangeable Al of the soils.

The quantities of organic matter were equivalent to 0 , 15,30 and $45 \mathrm{t} / \mathrm{ha}$, considering soil bulk density to be 1,5 and the depth of $20 \mathrm{~cm}$.

The soils utilized are from the Piracicaba Runicipality: 
Great Groun

Hydromorphic associated with or tho LVG

Terra noxa Estruturada, shallow phase

Roxo Latoso 1

Regoso1 intergrade to PVA Laras var.

Hydromorphic associated with PVA Laras var.
Séries

Três Municipios

Pau D'Alho

Ir acema

Cruz Alta

Formigueiro

The experiment was conducted in pots containing $1 \mathrm{Kg}$ of soil, under laboratory conditions. The soil was maintained in a moist condition (about $50 \%$ of its water retention capacity) for 30 days. After this period they were dried, grownd and sieved. Determination of pll, exchangeable Al and total $\mathrm{B}$ were done after wards.

The main results obtained can be summarized as follows:

a - The method of exchangeable $A 1$ indicated small quantities of lime, insufficient to completely eliminate the exchangeable Al from the soils. Only in the absence of orranic matter did it cause a raise in p? without causing any appreciable effects on total acidity.

b - Organic matter showed a general tendency to, raise soil pH, whereas its effect on exchangeable Al and total were doubt$\mathrm{fu} 1$. 
40.

7 - LITERATURA CITADA

ALMEIDA, J.P. : G. RANZANI e 0. VALSECHI, 1950. A vinhaça na Agricultura. 80 Congresso Internacional de Indústrias Agrí colas, Bruxelas. Boletim no 1 do Instituto Zimotécnico da E.S.A. "Luiz de Queiroz", Piracicaba, 20 Dp.

ALMEIDA, J。R.; G. RANZANI e 0. VALSECHI, sem data, 0 emprego da vinhaça na agricultura. 20 Congresso Mundial de Adubos Quimicos. Boletim no 2 do Instituto Zimotécnico da E. S.A. "Luiz de queiroz", Piracicaba, $16 \mathrm{pp}$.

CATAiNI, R. J. R. GALLO e H. GARGANTINI, 1955. Amostragem de solo, métodos de anälise, interpretação e indicaçōes gerais para fins de fertilidade. Boletim no 69 do Instituto Agronômico do Estado de São Paulo, Campinas, $29 \mathrm{po}$. 
CATARI, R. e 0. ALONSO, 1969. Avaliação da exigência de calcá rio do solo. Anais da E.S.A. Luiz de nueiroz 22: 141156 .

COELHO, F. A. S. e F. VERLEMGIA, sem data. Fertilidade do solo. Instituto Campineiro de Ensino Agrícola, vol.6, $384 \mathrm{pp}$., Campinas .

CORIS SÃO DE SOLOS. 1960. Levantamento de Reconhecimento dos Solos do Estado de São Psulo. Ministério da Agricultura, 634 Dp. Rio de Janeiro.

COMISSÃO ESTADUAL DE FERTILIDADE DE SOLOS, Sem data Recomendações de fertilizantes para Goiás. $4^{a}$ a aproximação. Empresa de Assistência Técnica e Extensão Rural do Estado de Goiás, Goiânia: 54 pp.

DO̊BEREIIER, J. e R. ALVAYYDO, 1966. Eliminação da toxidez de manganês pela matéria orgânica em solo "Gray Hidromórfico". pesq. Agronec. Bras. 1: 243-248.

EIRA, A. I. e P. C. T. CARVALZO, 1970. A decomposição da matéria orģânica pelos microrganismos do solo e sua influência nas variações do pll. Rev. Agric. 45: 15-21. S. Raulo.

GARGATTINI, H.:F,A.S. COELHO:F VERLENGIA e F. SOARES, 1970. Levantamento de Eertilidade dos solos do Estado de São Paulo. Instituto Agronômico do Estado de são Paulo, 32 pp. Campinas.

RAMPRATH, E. J., 1967. A acidez do solo e a calagem. (Traduzido por 0. Muzilii e R. E. Kalckman). International Soil Testing, Boletim Técnicon: 4,23 pp. 
MALAVOLTA, E. e T. COURY, 1954. Apostilas de präticas de cuímica Agrícola. Centro Acadeêmio "Luiz de Oueiroz Piracicaba.

MELLO, F. A. F., 1974. Sobre a correção da acidez de auatro solos por três diferentes processos. Rev. Agric。 $49: 68-74$.

MELLO, F. A.F. M. O.C. BRASIL SOBRINHO S. ARZOLLA e H. P. ISAAG, 1977. Capacidade amonificante de dois solos de campo cerrado do Estado de São Paulo. Rev. Agric. 52: 157-160.

MELLO, F. A.F., Não publicado. A relação pH $\times \mathrm{Al}^{3+}$ trocāvel do solo. A ser publicado na Revista de Agricultura.

MELLO, F。A.F.: M. O.C.BRASIL SOBRINHO : S. ARZOLLA : A. COBRA HTTTO e R. I. SILVEIRA, Sem data. Fertilidade, Fertilizantes e Fertilização do solo. Vol. I. Fertilidade do solo. Ed. Luiz de Oueiroz Ltda., 274 pp., Piracicaba

MFLLO, F.A.F. : R. F. SILVEIRA e S.R. HELLMEISTER, Não publicado. Efeitos de incorp̧oração de matéria orgânica sobre o pH e capacidade de troca catiônica de cinco solos do municipio de Piracicaba. Entregue para publicaço em Ecossistema.

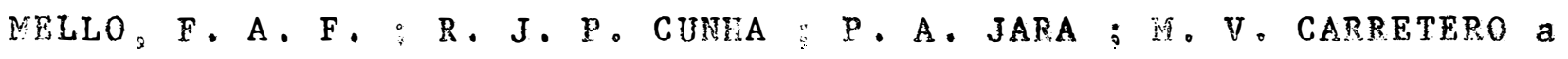
E. ZARBELLO JUNIOR e S.ARZOLLA, Não publicado. Efeitos da incorporação de restos de cultura de milho (Zea mays, L.) sobre algumas propriedades químicas e físicas de cinco sēries de solos do município de Piracicaba. A ser publicado na Revista da Agricultura.

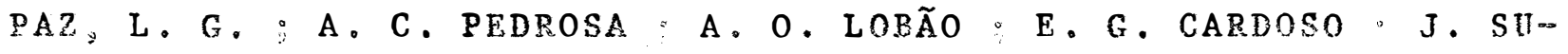
ZUYI M。A. SLEUTJES:S.A. L. FILHO e F. A.F。MFLLO, 1977. Efeitos da aplicação de torta de mamona sobre algumas proprie dades químicas de um Latosol Roxo e de um Regosol. Rev. Agric. 51: 207-213. 
PIPAEMG, 1972. Recomendacóes do uso de fertilizantes para o Es tado de Minas Gerais. Secretaria da Agricultura do Estado de Minas Gerais, Belo Horizontes, $88 \mathrm{n}$.

PITTA, G。V.E., 1974. Correção da acidez do solo utilizando o mêtodo do $\mathrm{Al}^{+3}$ trocável e efeitos dela decorrentes em seis unidades de solos. Dissertação, E. S. A. "Luiz de Oueiroz", Piracicaba.

RANZANI, G. 0. FREIRE e T. YINJO 1966. Carta de solos do Runicipio de Piracicaba. Centro de Estudos de Solos, ESALC, Piracicaba.

VALSECEI, 0. e F. PIMENTEL GOMES, 1954. Solos incorporados de vinhaça e seu teor em bases. Anais da E. S. A. "Luiz de Queiroz: 11: 135-150.

SERVIN, G. M., 1971. Estudos sobre a correção da acidez causada pelo $\mathrm{Al}^{3+}$ trocāvel em quatro solos e alguns efeitos dela decorrentes. Dissertaço, E. S. A. "Luiz de Oueiroz", 47 pp. Piracicaba

VAN RAIJ, B., 1975. Interpretacão da anälise de terra。 Instituto Agronômico do Estado de São Paulo, Campinas, mimeog. $8 \mathrm{pp}$.

YENNY, H. 1946. Factors of Soil Eormation, 1. ed. McGrawHil1 Book Company. Inc. New York and London, 281 pp.

ZAGO E. A. G. MATSUI $\because$. T. MIRANDA; J.D.VARGAS e F.A. F. PEllo, não publicado. Efeitos da adição de torta de ma mona sobre algumas propriedades de dois Latossolos do Estado de São Paulo. A ser publicado na Revista de Agricultura. 